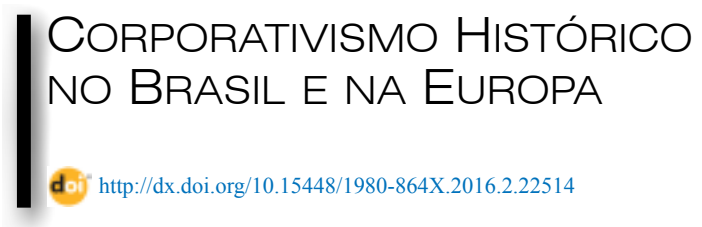

\title{
Corporativismo à Brasileira: entre o autoritarismo e a democracia*
}

\author{
Brazilian Corporatism: \\ between authoritarianism and democracy \\ Corporativismo Brasileño: \\ entre autoritarismo y democracia
}

Valéria Marques Lobo***

\begin{abstract}
Resumo: O artigo analisa a relação entre corporativismo e democracia, de uma perspectiva histórica. No plano mais geral, a literatura a respeito desse tema destaca que, embora o corporativismo tenha suas origens associadas a contextos autoritários, formas corporativas de intermediação de interesses adaptaram-se a conjunturas democráticas. No caso brasileiro, embora tenha sua gênese vinculada ao propósito de controle estatal sobre o conflito social, durante o primeiro governo Vargas, seu desenvolvimento coincide com o arrefecimento do autoritarismo nos últimos anos do Estado Novo. Desde então, atravessou diferentes sistemas políticos, conviveu com distintas constituições, e tem parte importante de seus dispositivos presentes ainda hoje. Por outro lado, a despeito de ser alvo frequente de críticas, emanadas da direita à esquerda do espectro político brasileiro, nenhum de seus críticos revelou uma preferência intensa pela superação do modelo. Diante disto, indaga-se a respeito da pertinência das proposições orientadas para sua supressão ou se, de outra forma, não seria mais viável postular o aprimoramento dos dispositivos corporativos ainda presentes, visando o aperfeiçoamento da democracia no país.
\end{abstract}

Palavras-chave: corporativismo; autoritarismo; democracia

Abstract: This article analyzes the relation between corporatism and democracy, in a historic perspective. In general, the literature about this subject points out that despite being the corporatism's origins associated with authoritarian contexts, the corporate

\footnotetext{
*A pesquisa que resultou neste artigo contou com financiamento da Coordenação de Aperfeiçoamento de Pessoal de Nível Superior (CAPES).

**Professora do Departamento de História da Universidade Federal de Juiz de Fora (UFJF). <valerialobo.ufjf@gmail.com> <dados biográficos/biographic data>
} 
forms to intermediate interests have adapted to democratic situations. In the Brazilian case, although the corporatism genesis was linked to a state control over the social conflicts in the Vargas government, its development matches the last years of the 'Estado Novo'. Since then, corporatism has crossed different political systems in Brazil, and still has important mechanisms working today. On the other side, despite being a frequent target of critics from the left and the right, none of the critics showed a strong preference to overcome this model. This point leads questions about the relevance of the propositions to remove it, or to postulate improvements in this policy, looking forward to also improve the democratic state.

Keywords: corporatism; democracy; authoritarianism

Resumen: El artículo analiza la relación entre el corporativismo y la democracia, desde una perspectiva histórica. En el nivel más general, la literatura sobre este tema señala que, mientras el corporativismo tiene sus orígenes asociadas a contextos autoritarios, otras formas corporativas de intermediación se adaptaran a escenarios democráticos. En Brasil, aunque su génesis estuviera ligada a los efectos del control estatal sobre los conflictos sociales en el primer Gobierno de Vargas, su desarrollo coincide con el enfriamiento de lo autoritarismo en los últimos años del Estado Novo. Desde entonces sobrevivió a través de diferentes sistemas políticos, y mantuvo una parte importante de sus dispositivos presentes en la actualidad. Por otro lado, a pesar de ser un objetivo frecuente de crítica de la derecha y de la izquierda, nadie mostro una fuerte preferencia por superar ese modelo. Teniendo en cuenta esto, si se le pregunta acerca de la relevancia de las proposiciones que piden su eliminación, o de otra manera, si ya no sería viable buscar la mejora de los dispositivos corporativos que siguen presentes, así a mejorar el propio sistema democrático.

Palabras clave: corporativismo; democracia; autoritarismo

\section{Introdução}

A forma como se implanta a ordem sindical corporativa no Brasil não é, por certo, o único, nem o principal obstáculo no caminho da construção da democracia brasileira. Há uma vasta literatura que discute a questão, ainda que não diretamente, e que tende a localizar tal dificuldade em polos opostos.

$\mathrm{Na}$ história do pensamento político brasileiro, situam-se, de um lado, os que apontaram a prevalência do poder privado como um fator a obstar a emergência de formas tipicamente democráticas de representação, dado o predomínio do localismo e das formas oligárquicas de dominação. De outro, os que atribuíram à formação de uma estrutura estatal de natureza patrimonialista, que precede a emergência de grupos sociais e os integra à lógica estatal através da cooptação antes que se desenvolvessem organismos autônomos de articulação e representação de interesses, a principal dificuldade para a consolidação da demo- 
cracia $^{1}$. De comum a estas vertentes, a indicação do predomínio de formas clientelistas aparecia como um fator inibidor do desenvolvimento da democracia no país.

Com outra perspectiva, nos anos 50, através das formulações do ISEB, desenvolveu-se uma certa confiança de que os processos de urbanização e industrialização criariam os requisitos necessários à consolidação da democracia ${ }^{2}$. Sob o regime militar, estes termos se inverteram. Retomando formulações típicas do pensamento autoritário dos anos 30, a Doutrina de Segurança Nacional indicava como necessária a presença de um interregno autoritário que, modernizando o país, o preparasse para o advento da democracia ${ }^{3}$.

Desde então, o debate acerca das possibilidades e limites da democracia no país ampliou-se e diversificou-se, destacando elementos variados, seja a origem escravista de nossa formação social, seja as características da ordem institucional brasileira, seja o caráter "pelo alto" da formação capitalista no país ${ }^{4}$.

Quanto ao corporativismo, desde seu surgimento consiste em objeto de críticas, emanadas tanto dos meios acadêmicos, como dos meios políticos e de entidades da sociedade civil. Embora a literatura há muito reconheça a possibilidade de adaptação de organismos de matriz corporativista a ambientes notadamente democráticos ${ }^{5}$, predominam os estudos voltados para o desenvolvimento do corporativismo em regimes autoritários. Para além das fronteiras da academia, as críticas advém da direita à esquerda do espectro político brasileiro e em geral apontam os obstáculos que o corporativismo representa para a realização plena da democracia no país. Os últimos anos da ditadura civil-militar instalada em 1964 coincidem com o momento em que a crítica ao arcabouço corporativo foi mais contundente e a supressão do modelo parecia mais consensual. A despeito de setores do movimento sindical defenderem sua permanência, o chamado Novo Sindicalismo, movimento que alcançou maior visibilidade no período e deu origem à CUT (Central Única dos Trabalhadores), ganhou as ruas e conquistou elevados índices de adesão

\footnotetext{
${ }^{1}$ Na primeira perspectiva, destaca-se o trabalho de Duarte (1939) e na segunda a obra de Faoro (1958), cuja perspectiva central foi retomada em Scwartzman (1982).

${ }^{2}$ Sobre o ISEB, cf. TOLEDO, 1982.

${ }^{3}$ Sobre o pensamento autoritário dos anos 30, cf. SANTOS, 1978. Uma síntese da Doutrina de Segurança Nacional, encontra-se em ALVES, 1984.

${ }^{4} \mathrm{Na}$ literatura dedicada ao tema da democracia em conexão com a transição recente no país, destacam-se, por exemplo, dois trabalhos coletivos organizados em meio ao processo de transição: CAMARGO; DINIZ,1989 e REIS; O’DONNELL, 1988.

${ }^{5}$ Conferir a tipologia proposta por Philippe C. Schmitter (1974).
} 
defendendo a autonomia dos sindicatos. A conjuntura era propícia e a bandeira da liberdade sindical encaixava-se perfeitamente na luta pela redemocratização. Neste ponto, cabe um breve recuo no tempo para situar a questão.

Há quase 40 anos, em 1977, o DIEESE denunciou a manipulação do índice oficial de inflação de $1973^{6}$, artifício responsável por acentuar a contenção dos salários no período, num ambiente em que os sindicatos eram dirigidos por lideranças governistas. A divulgação teve ampla repercussão e jogou água no moinho do recrudescimento da organização dos trabalhadores, sobretudo dos principais centros industriais do Brasil. Nascia o Novo Sindicalismo, que ao lado de outros movimentos sociais e entidades da sociedade civil agitou a bandeira da redemocratização do país, processo que no decorrer dos anos 1980 envolveu um conjunto de demandas que oferecem os contornos de uma democracia política e social.

A Constituição de 1988 é o desaguadouro dessa imensa onda de protestos que marcou o período. Para o Novo Sindicalismo, a conquista da democracia supunha, ademais de todas as questões que compartilhava com os outros movimentos sociais, a superação da ordem corporativa, associada ao ambiente sindical autorizado pelos militares e aos pelegos do pré-64. Aos olhos das lideranças do Novo Sindicalismo, formados sob o regime militar e, por conseguinte, com baixo nível de informação a respeito do que havia sido a vida associativa dos trabalhadores entre 1945 e 1964, cuja memória a ditadura havia buscado subtrair, pois bem, para aquelas lideranças tudo aquilo que se associava ao trabalhismo, tornado populismo no plano de um certo discurso voltado para a sua desconstrução (REIS FILHO, 2001), deveria ser suplantado. Por outras palavras, empunhavam a bandeira da liberdade de organização, a qual passaria não apenas pelo fim da prerrogativa estatal de intervir nos sindicatos, mas pela ruptura com todo o ordenamento legado do Estado Novo, que teria sido responsável por amortizar o conflito de classes no pré-64 e transformado as lideranças trabalhistas em pelegos. Na mira estavam, sobretudo, o Imposto e a Unicidade Sindical, bem como o poder normativo da Justiça do Trabalho, dispositivos situados

\footnotetext{
${ }^{6}$ As informações contidas na denúncia foram reconhecidas como verdadeiras pelo Banco Mundial. Uma ação do movimento sindical e da oposição ao regime militar abriu uma extensa discussão em torno do assunto, desdobrando-se em uma CPI (Comissão Parlamentar de Inquérito), instalada na Câmara Federal. A denúncia teve grande repercussão na imprensa brasileira. (Disponível em: $<$ http://memoria.dieese.org.br/museu/navegacao/linha-do-tempo/anos-70>. Acesso em: 30 nov. 2015).
} 
na base da estrutura corporativa e responsáveis pelo atrelamento dos sindicatos ao Estado. Era preciso e urgente inaugurar um novo modelo de organização, romper com toda aquela estrutura, inclusive física, para promover um novo estilo de relação com o patronato, subtraindo-se qualquer possibilidade de ingerência governamental. Na prática, esse discurso consubstanciou-se nas chamadas oposições sindicais, as quais, uma vez conquistado o reconhecimento das bases e a vitória eleitoral, assumiram a direção do sindicato oficial (LOBO, 1995).

Desde então, a luta contra o Imposto e a Unicidade esmoreceu. Embora jamais tenha perdido seu lugar na agenda sindical, comparecendo inclusive em quase todas as resoluções dos congressos nacionais da CUT, a demanda perdeu o vigor no decorrer dos anos 80. A título de exemplo, em 85, quando o ministro do trabalho, Almir Pazzianotto, propôs uma reforma da estrutura sindical com base na ratificação da Convenção 87 da OIT (Organização Internacional do Trabalho), que recomendava a liberdade sindical, a CUT manifestou seu apoio unicamente através de algumas notas circuladas na imprensa, em contraste com a postura altamente militante da CGT, que era contrária à proposta de Pazzianotto. $\mathrm{O}$ resultado foi a permanência dos eixos estruturantes do sindicalismo oficial. Este mesmo procedimento pouco ofensivo da CUT em relação à transformação da estrutura sindical pode ser observado por ocasião da elaboração da Constituição de 1988. Neste período, várias conquistas foram alcançadas, por pressão da CUT, que promoveu manifestações dentro e fora do Parlamento Nacional. Todavia, no dia da votação da Unicidade Sindical não havia mais que vinte sindicalistas nas galerias do Congresso para pressionar por sua supressão. Além disto, a aprovação da manutenção da unicidade não foi acompanhada de protestos significativos por parte da CUT (LOBO, 1995) 7 .

Desta forma, a contradição entre o discurso da Central e sua prática quotidiana salta aos olhos e permite formular a hipótese de que na ordem das preferências cutistas a ruptura com a estrutura sindical jamais ocupou lugar de destaque. Com efeito, apesar das centrais sindicais atuarem paralelamente à estrutura oficial, e até recentemente não disporem da prerrogativa de participar das negociações coletivas,

\footnotetext{
${ }^{7}$ Após a Constituição de 1988, a preservação da contribuição sindical compulsória acabou contribuindo para a pulverização dos sindicatos. A unicidade foi mantida, mas com a alteração da definição de categoria profissional tornou-se possível a criação de sindicatos menores. É provável que a criação de determinados sindicatos tenha sido motivada pela existência da contribuição (tal como acontece com o Fundo Partidário). De modo que é possível formular a hipótese de que a manutenção de tal contribuição favoreceu a pulverização, em detrimento da centralização dos sindicatos, contribuindo para o enfraquecimento da ação coletiva de determinadas categorias.
} 
exercem grande influência e organizam o discurso e mesmo a prática dos sindicatos oficiais. Tal relação, aparentemente esquizofrênica, resultou em inúmeras conquistas para a classe trabalhadora, assegurando inclusive o poder de veto às proposições orientadas pela perspectiva de desregulamentar as relações de trabalho que tiveram lugar sobretudo na década de $1990^{8}$.

Diante disso, cumpre indagar em que medida a efetivação da democracia passa pela ruptura com o corporativismo? Em outras palavras, em que medida a democracia é compatível com o corporativismo nas condições brasileiras? A estreita relação entre corporativismo e autoritarismo é mais óbvia, embora haja muito ainda a se investigar. Mas perscrutar acerca da viabilidade da democracia brasileira a despeito da permanência dos traços corporativos que marcam a história das relações sociais no país, tal como se pretende aqui, me parece oportuno. Antes de prosseguir, cumpre destacar que a presente abordagem limita-se a discutir um único aspecto do corporativismo, referente à estrutura sindical, embora outros aspectos sejam mencionados, mas apenas de forma suplementar. Além disso, cumpre salientar que, embora reconheça que muitas vezes seja mais apropriado utilizar a chave proposta por Eduardo Noronha e referir-se ao sistema brasileiro de relações sociais não como corporativista, mas como legislado, em contraposição ao modelo negociado (NORONHA, 2000), considero que há organismos e regulamentos na burocracia estatal e na estrutura sindical de matriz tipicamente corporativista, ainda que se possa concordar com a assertiva, segundo a qual, o corporativismo jamais se completou no Brasil. Antes de abordar o caso brasileiro, cabe uma breve incursão na trajetória que conduziu à convergência entre democracia e corporativismo em parte do ocidente europeu no segundo pós-guerra.

\section{Corporativismo e democracia no ocidente europeu}

No decorrer do século XX, desenvolveram-se dois modelos de estruturação das relações políticas e sociais, que a despeito das críticas e das crises ocasionais seguem fornecendo instituições para boa parte das sociedades ocidentais até os dias atuais. Trata-se da Democracia Representativa e do Corporativismo. Embora os mecanismos de cada um desses modelos já estivessem presentes desde o início daquele

\footnotetext{
${ }^{8}$ Em relação ao veto à desregulamentação refiro-me especificamente à CUT, uma vez que a outra central de peso nos anos 90, a Força Sindical, defendia abertamente a flexibilização da legislação trabalhista. (LOBO, 2010)
} 
século, e no caso do corporativismo bem antes disso, suas engrenagens só puderam se completar a partir da crise dos anos 30 e, ainda assim, em poucos casos proporcionaram pleno e exclusivo funcionamento a um ou outro modelo. Quanto ao corporativismo, em seus primórdios, serviu quase sempre para legitimar a ordem autoritária, ainda que em alguns casos tenha funcionado apenas parcialmente. No entanto, no segundo pós-guerra, revelou-se compatível com a chamada Democracia Liberal, tornando-se funcional no sentido de contribuir para reduzir os efeitos econômicos que uma possível polarização engendrada pelo fortalecimento das organizações dos trabalhadores poderia produzir. Nesta seção, percorre-se a trajetória que conduziu ao encontro dos dois modelos.

A adoção generalizada do sufrágio universal nas sociedades de capitalismo mais antigo é observada somente a partir do entre-guerras, como resultado das pressões exercidas pelo movimento operário. A conquista do sufrágio, acompanhada pela entrada na competição política dos partidos ideológicos anticapitalistas, surgidos em fins do século XIX, acabou por produzir efeitos em boa medida inesperados do ponto de vista das correntes liberais. Diante da necessidade de angariar um número progressivamente maior de apoios, dada a competição eleitoral, os partidos políticos se distanciaram dos ideais em torno dos quais foram criados e desradicalizaram-se, ficando cada vez mais remota a possibilidade de ruptura, por via de uma ação destes partidos, com as estruturas mantenedoras do desenvolvimento capitalista. Nesta medida, a democracia representativa de massas acabou por se revelar funcional para a evolução do capitalismo (OFFE, 1984). Tal processo revelouse central nas discussões teóricas intra e extrapartidárias no início do século XX.

Em 1914, Robert Michels (1982) intuiu que a dilatação dos espaços democráticos acabaria por resultar, necessariamente, na oligarquização destes espaços. Em seu estudo acerca dos partidos políticos, sobre o partido socialdemocrata alemão em particular, Michels observou que havia uma tendência inerente a estes organismos, próprios das democracias modernas, de se transformarem de partidos de opinião em partidos organizadores.

A observação de Michels, embora direcionada particularmente aos partidos políticos, estendia-se aos aspectos gerais da sociedade. Nesta acepção, a evolução da democracia tenderia a tornar os organismos de intermediação e de representação de interesses - entre os quais encontram-se o sindicato e o partido político - progressivamente 
numerosos, contribuindo para sua oligarquização. Em meio a esse processo ocorreria o distanciamento entre lideranças e bases, as quais perderiam progressivamente a capacidade de influenciar a agenda do partido, e sua participação assumiria progressivamente o caráter do que Max Weber chamou de aprovação plebiscitária das massas. Por outro lado, o processo indicado por Michels envolve uma tendência em curva declinante da circulação das lideranças, provocada pelo crescimento dos partidos. Ao se transformarem em grandes aparelhos, esses provocam, simultaneamente, o apego dos líderes à máquina partidária e o afrouxamento da correspondência entre os verdadeiros interesses dos grupos que originariamente compunham suas bases e as propostas que são encaminhadas e defendidas pelo partido no plano institucional.

Por outro lado, a redução do radicalismo, o qual tende a caracterizar a atuação sobretudo dos partidos ideológicos antes de seu ingresso na competição política, favoreceu a aceitação pela burguesia da ampliação dos espaços democráticos. Desta forma, uma espécie de contrato marcaria boa parte das sociedades da Europa Ocidental em meados do século XX e estabeleceria os direitos sociais, as políticas redistributivas, que constituem a terceira etapa da evolução da cidadania tal como descrita por T. H. Marshall. (1967) A ideia de contrato aqui funda-se na constatação de que a introdução dos direitos sociais não se relaciona apenas ao bem estar de seus beneficiários imediatos. Sabe-se que a adoção de políticas keynesianas envolveu uma preocupação com o baixo consumo e, portanto, com o próprio desenvolvimento capitalista. Aos olhos do Capital, a fixação de direitos sociais apareceria como um meio de ampliar o consenso em torno do capitalismo entre as camadas assalariadas.

Portanto, a compatibilidade entre capitalismo e democracia na parcela ocidental do continente europeu passou pela integração dos partidos de esquerda à arena eleitoral. A partir do momento em que admitiram compartilhar das regras básicas para o funcionamento adequado da instituição parlamentar, os partidos operários de massa acentuaram seu processo de desradicalização e burocratização, afastando-se progressivamente dos ideais em torno dos quais foram criados, minimizando, assim, os eventuais prejuízos que sua ação poderia produzir para a continuidade do desenvolvimento capitalista.

$\mathrm{O}$ processo indicado por Michels a respeito dos partidos políticos corresponde ao que Offe e Wiesenthal denominaram de apego do artefato da forma em si mesma e ao ciclo organizacional das entidades sindicais (OFFE; WIESENTHAL, 1984). Por suposto, o crescimento 
dos sindicatos tenderia a ser acompanhado pela redução, entre seus dirigentes, da necessidade de provocar em seus membros disposição para agir, perdendo, assim, o caráter dialógico que, no limite, é o que asseguraria a democracia interna das organizações.

A ampliação dos sindicatos, decorrente da necessidade de angariar um volume de apoios que lhes possibilitasse exercer poder de barganha sobre o empresariado e o Estado, promove uma certa acomodação das lideranças sindicais. Nos países de capitalismo avançado, este processo de acomodação ocorre após um longo período marcado pelo embate entre capital e trabalho, que resultou na conquista de diversas vitórias para a classe trabalhadora. Estas conquistas, associadas à constatação de que a superação do capitalismo dificilmente se consumaria, produziram, entre os assalariados, um certo consenso quanto às virtudes do capitalismo. Nesta medida, ocorre a desradicalização da luta operária e os procedimentos reivindicativos, tanto dos sindicatos como dos partidos políticos, adquirem contornos que os tornam compatíveis com o desenvolvimento capitalista. As demandas das camadas assalariadas passam a ser elaboradas levando-se em conta fatores que extrapolam o âmbito dos interesses dos trabalhadores, tais como as taxas de crescimento do capitalismo, dos lucros etc. (PZERWORSKI, 1989).

Por seu turno, os empresários aceitam ceder às demandas advindas do movimento operário, já que o arrefecimento da luta operária anticapitalista favoreceria a continuidade do desenvolvimento capitalista. A social-democracia apresentar-se-ia, assim, como o resultado de um jogo de soma positiva, onde ambos os atores envolvidos angariaram benefícios.

Deve-se acrescentar à equação acima seu elemento corporativo potencial. A conquista do Welfare State implicou, em alguns países europeus, na adoção de arranjos corporativos para a regulação de preços e salários e para a viabilização das políticas de pleno emprego. Tal se verificou, conforme Panitch (1981), naqueles países de movimento sindical notadamente centralizado. Este arranjo, contudo, não eliminava a ação dos partidos, que serviam para a negociação de políticas compensatórias, referentes à previdência e assistência social, na esfera parlamentar. Além disto, embora servindo às políticas de estabilização e à aquisição de previsibilidade, exigências do capitalismo monopolista, o corporativismo se constitui a partir de negociações travadas por entidades autônomas. Tal modelo serve à obtenção das bases materiais do consentimento, que conferiu legitimidade ao Welfare 
State (PZERWORSKI, 1989). Assim, a construção da social-democracia em algumas situações europeias ocorreu de forma quase simultânea ao estabelecimento de estruturas neocorporativas, situadas em meio ao processo de transição do capitalismo competitivo para o capitalismo organizado ${ }^{9}$.

Não obstante os inegáveis progressos que proporcionou em termos de bem estar e de sido determinante na solução da crise pós-Guerra, e ainda que não se tenha gestado uma alternativa capaz de produzir elevados índices de adesão, o Estado Social já não se reveste do caráter consensual que marcou seus primórdios. As críticas possuem matrizes diversas. Os liberais o acusam de agravar os conflitos da sociedade de mercado, impedindo que as forças da paz social e do progresso funcionem de maneira adequada e útil. A pesada carga de impostos sobre o capital representaria um desestímulo ao investimento produtivo e os benefícios sociais proporcionados aos trabalhadores proporcionariam um desestímulo ao trabalho. A solução seria uma desregulamentação progressiva (OFFE, 1991, p. 116).

Para setores da esquerda, o Estado social teria se tornado ineficiente e mesmo repressor, gerando uma concepção falsa na classe trabalhadora sobre a realidade política e social. Desta forma, ele seria antes um meio para estabilizar a sociedade capitalista do que um passo para transformá-la (OFFE, 1991, p. 123). Tal crítica assenta-se na noção de que o Estado de bem-estar pouco teria contribuído para modificar estrutura de distribuição de renda; além de ter-se tornado pesado, pois antes de atuar na solução dos problemas em suas origens, ele produziria apenas políticas compensatórias, que são sempre mais caras e menos efetivas.

Foge ao escopo deste artigo especular sobre o futuro daqueles arranjos, cuja análise funciona aqui apenas como parâmetro para refletir sobre o caso brasileiro. Nesse sentido, considerar a trajetória das democracias mais antigas implica levar em conta também os limites daquele modelo. De todo modo, cumpre ressaltar que, a despeito das críticas, em diversas realidades nacionais o Estado Social se constituiu paralelamente ao desenvolvimento de dispositivos corporativistas, conformando-se um arranjo que consiste, talvez, na melhor expressão da compatibilidade entre democracia e corporativismo.

${ }_{9}^{9}$ Sobre este processo, além das obras citadas de OFFE, 1984; PANITCH, 1981; e PZERWOSKI, 1989; cf. REIS, 1988. 


\section{Corporativismo no Brasil: das origens à democracia de 1946}

O tempo histórico que assiste à emergência da ordem capitalista é crucial para o entendimento do formato que esta assume no decorrer de seu desenvolvimento. Em sua análise sobre o processo de "modernização conservadora", Moore destacava o atraso relativo da Alemanha diante de outras Nações para explicar o caráter autoritário da transformação ali verificada. (MOORE JR, 1975) Comprimida pela necessidade de acelerar o processo de industrialização num ambiente impactado por uma forte presença operária e socialista, a burguesia alemã não reproduziu o esquema de alianças que procedeu à eliminação do Ancién Regime na França. Antes, optou por uma aliança subordinada com a burocracia estatal e os grandes proprietários para proceder a uma aceleração da acumulação industrial e a uma transformação molecular da ordem institucional, de modo a adequá-la às exigências da livre contratação, indispensável à operação da economia capitalista.

Tal imagem aproxima-se do caso brasileiro, ao qual deve-se adicionar a origem colonial e escravista de nossa formação social. Estes dois elementos explicam a particularidade do processo de formação do capitalismo no país que, além de retardatário, é também dependente. $\mathrm{O}$ caráter colonial de nossa formação histórica favoreceu uma excessiva concentração das atividades econômicas em alguns pólos dinâmicos vinculados à produção exportadora. Com isto, o espaço econômico brasileiro não se articulava plenamente através de relações mercantis e contratuais. Na maior parte do território brasileiro prevaleciam formas variadas de dependência pessoal que, associadas ao último elemento indicado acima, dificultavam a constituição de formas modernas de articulação de interesses e o desenvolvimento de processos de circulação de informações que pudessem sedimentar uma "opinião pública" e a efetiva competição pluralista. Por seu turno, em suas fases iniciais a estrutura industrial brasileira vinculou-se diretamente aos dinamismos da economia exportadora, da qual dependia tanto na geração de capitais quanto na constituição do mercado. (MELLO, 1984) Por fim, dado o atraso do processo de industrialização, em tais pólos dinâmicos verificouse a fixação de grandes empresas industriais, instaladas com tecnologias disponíveis no mercado mundial, engendrando a formação de um contingente de trabalhadores industriais precocemente concentrados ${ }^{10}$.

${ }^{10} \mathrm{O}$ predomínio da grande indústria na estrutura social brasileira foi destacado inicialmente por SILVA, 1976. 
Ademais, a ordem institucional estabelecida no Brasil desde 1889 assegurava as condições para a expansão industrial, em que pese a pequena influência que os industriais podiam ter sobre o Estado, em função da vigência do domínio oligárquico ${ }^{11}$. Por sua vez, a economia escravista não engendrava um campesinato dinâmico, equivalente ao elemento camponês da sociedade feudal, decisivo nas revoluções democráticas na Europa (VELHO, 1976). Assim, era baixo o nível de tensão entre oligarquias agrárias e industriais, enquanto o movimento operário revelava níveis acentuados de combatividade, ainda que circunscritos a poucas regiões do país.

A crise do "modelo agro-exportador" e a desarticulação do pacto de dominação oligárquico criaram novas exigências, favorecendo, particularmente após 1933, a intensificação dos processos de urbanização e industrialização ${ }^{12}$. Desta forma, ampliava o contingente dos trabalhadores industriais e abria possibilidades para a generalização das atitudes típicas do movimento sindical do período anterior, conforme atesta a intensificação das lutas operárias até 1935 (VIANNA, 1999). Do mesmo modo, novos atores ganhavam relevância na cena política, exigindo da recém reforçada burocracia de Estado a constituição de mecanismos de incorporação política, incompatíveis com o formato oligárquico que assumia a ordem liberal brasileira (MARTINS, 1983).

É consensual na historiografia que o corporativismo foi a forma encontrada para responder a essas pressões. A decantada crise de hegemonia que ocorreu no período acentuava o peso da burocracia de Estado, que, através do modelo corporativo e da ampliação do aparato burocrático do Estado, simultaneamente atendia aos reclamos de participação das frações oligárquicas submetidas à condição de subalternidade na Primeira República, às pressões dos industriais para participarem mais intensamente da formulação da política econômica governamental e à incorporação política do movimento operário, mas com o alijamento das formas de organização e das lideranças dominantes no período anterior.

${ }^{11}$ Sobre a compatibilidade da ordem institucional presente na República Velha e a expansão capitalista, ver, por ex., VIANNA, 1999. A propósito do comportamento político do empresariado industrial no regime oligárquico, ver DINIZ, 1978; GOMES, 2014.

12 O debate sobre a intenção industrializante da política econômica de Vargas até 1937 foi suscitado pelos trabalhos de Pelaez (1971); Villela e Suzigan. (1973) Estes autores enfatizavam que a natureza ortodoxa da política monetária e cambial no período atingia negativamente a indústria. A indicação dos efeitos industrializantes da política econômica de Vargas tem sua matriz na clássica análise de Furtado (1975) segundo a qual a política de defesa do café combinada à proibição de novos plantios - com liberação, pois, de capital para novas atividades - permitiu a sustentação do nível de renda interna e o estímulo à produção industrial. 
$\mathrm{O}$ processo de industrialização que se segue, seja enquanto "industrialização restringida", seja na industrialização pesada dos anos 50, não opõe os setores agrários aos industriais (MELLO, 1984; OLIVEIRA, 1981). Para os primeiros, assegurava-se preservação das formas de dominação já existentes no campo brasileiro, como uma espécie de compensação à reorientação das ações do Estado no sentido da industrialização, clara a partir de 1937. Quanto ao movimento operário, submetido à estrutura corporativa, deixava de existir como ator autônomo. O caráter retardatário da formação do capitalismo no Brasil, ao lado de exigir uma forte presença do Estado e a transferência de recursos gerados no polo exportador - via confisco cambial -, implicaria também na contenção dos salários dos trabalhadores industriais. Para garanti-la tornava-se necessária a interdição da ação operária autônoma. Tal papel caberia à estrutura sindical corporativa, tal como foi montada no Brasil.

Subjacente à legislação que deu origem à estrutura corporativa, havia a intenção de suprimir os conflitos entre as classes e substituí-los por uma estrutura que possibilitasse a cooperação entre os diversos setores sociais no sentido de facilitar a implementação da política de industrialização nacional em bases legítimas, isto é, sobre o consenso aparente das camadas sociais envolvidas nesse processo. Assim, no momento inicial da trajetória de constituição da estrutura sindical corporativa brasileira, o propósito de impor um caráter heterônomo aos sindicatos é nítido, exprimindo a natureza autoritária do modelo que estava em vias de construção.

A montagem da estrutura sindical corporativa não resultou, contudo, de um projeto pré-concebido, mas, antes, da fixação de sucessivos regulamentos, alguns dos quais emblemáticos, a exemplo da Lei de Sindicalização, de 1931, que prescrevia que os sindicatos “(...) deveriam servir de pára-choques entre as tendências conflitivas nas relações do capital com o trabalho (...) definindo o sindicato como um órgão de colaboração com o poder público" (VIANNA, 1999, p. 146).

A partir deste decreto, proibiu-se toda propaganda ideológica dentro dos sindicatos, que tiveram seu conteúdo reivindicativo suprimido. As entidades sindicais foram revestidas da função de negociar com a representação empresarial - sob mediação do Ministério do Trabalho os assuntos de interesse de ambos os setores, através das Comissões Mistas de Conciliação e Arbitragem (GOMES, 2014). Entretanto, a eficácia desta medida ficou comprometida pela natureza facultativa da participação empresarial nas convenções coletivas de trabalho. Nestes 
termos, o colaboracionismo pretendido pelo Estado ficou inviabilizado e os sindicatos reconhecidos pelo Estado foram progressivamente esvaziados (VIANNA, 1999).

Neste período, os anarquistas e comunistas eram hegemônicos no movimento sindical e a introdução do controle estatal sobre os sindicatos, somada à criação de novas entidades, visava exatamente romper com esta hegemonia e substituir o sindicalismo classista pelo sindicato colaboracionista (VIANNA, 1999). Esta intenção aparece nitidamente no discurso do então ministro do trabalho, Lindolfo Collor: "já é hora de substituir o velho e negativo conceito de luta de classes pelo conceito novo, construtivo e orgânico de colaboração de classes".

Todavia, a resistência de antigas lideranças em aderir à nova estrutura aprofundava as dificuldades de institucionalização do modelo e o índice de sindicatos reconhecidos pelo Ministério do Trabalho permaneceu baixo durante boa parte da década de 30 (VIANNA, 1999). $\mathrm{Na}$ ausência de bases materiais capazes de proporcionar o consentimento da totalidade dos setores envolvidos no processo de industrialização, a implementação do corporativismo implicou na adoção de procedimentos coercitivos sobre a parcela organizada que resistiu à imposição do Estado de transformar os sindicatos em órgãos subordinados ao Ministério do Trabalho. Tal ocorreu inclusive nas regiões periféricas, onde havia baixo índice de organização autônoma. Os dados coligidos por Vianna (VIANNA, 1999, p. 144) indicam que o volume de adesões ao sindicato oficial variou na razão direta dos procedimentos coercitivos adotados.

Assim, em meados dos anos 1930, enquanto por vias legais e benefícios materiais o governo buscava atrair os trabalhadores para a sua órbita, noutra frente a ação repressora agia sobre os casos mais resistentes. O período situado entre 1935 e 1937, sob a vigência da Carta Constitucional de 1934, que previa o pluralismo e a autonomia sindical, foi, paradoxalmente, marcado pela perseguição às lideranças dos organismos que até então haviam conseguido manter o seu funcionamento à margem do sistema oficial. Boa parte dos sindicatos autônomos foram fechados e suas lideranças presas. Como os sindicatos oficiais não ofereciam atrativos, já que encontravam-se despidos de ação reivindicativa, boa parte dos trabalhadores na década de 30 permaneceu desvinculada das entidades sindicais oficiais.

Com a Constituição de 1937, verifica-se um aprofundamento do atrelamento dos sindicatos ao Estado, garantindo um amplo e continuado controle do Estado sobre os organismos sindicais. No entanto, não foi suficiente para garantir o controle desejado sobre o amplo contingente de 
assalariados não sindicalizados, que constituía uma parcela significativa dos trabalhadores brasileiros. Assim, de acordo com a avaliação governamental, o controle por via de mecanismos repressivos deveria ser substituído por procedimentos que assegurassem a legitimidade das ações estatais, buscando a adesão da sociedade. Deste modo, o corporativismo apresentar-se-ia como uma alternativa ao liberalismo político, mas buscaria legitimar-se por via de procedimentos esvaziados, pelo menos de modo aparente, de conteúdo autoritário.

É assim que, no curso da política de introdução do modelo sindical corporativo, o imposto sindical revela-se um fator de fundamental importância para o sucesso do programa. Antes dele, várias medidas foram adotadas, mas nenhuma delas foi capaz de produzir a adesão dos trabalhadores, mitigando o caráter legitimador que se pretendia imprimir no novo formato organizacional. Ao possibilitar aos sindicatos a prestação de serviços materiais que beneficiavam diretamente os indivíduos associados, o imposto sindical ganhou uma relevância sem precedentes e foi responsável pelo aumento progressivo do volume de indivíduos filiados aos sindicatos oficiais, facilitando, por suposto, o controle do Estado sobre as camadas assalariadas (GOMES, 2005a).

Em 1939, o Estado havia ampliado as funções dos sindicatos, atribuindo-lhes, para além do papel singular de ente colaboracionista, uma extensa pauta de tarefas assistenciais, com o objetivo primordial de despertar o interesse dos trabalhadores pelos sindicatos oficiais e transformá-los em entidades representativas. Todavia, o cumprimento da lei sindical de 1939 revelou-se inicialmente inviável, diante da ausência de uma infraestrutura adequada à prestação dos serviços, impossível de erigir-se apenas por meio dos limitados recursos gerados pelos próprios sindicatos. Os sindicatos continuariam funcionando precariamente e pouco teriam a oferecer às suas bases.

No ano seguinte, entretanto, através do Decreto-Lei 2337, de 08 de julho de 1940, o Estado regulamentou o imposto sindical, tornando possível aos sindicatos o cumprimento da legislação de 1939. A partir daí, os sindicatos puderam ampliar suas sedes e oferecer atendimento médico, odontológico e jurídico a seus associados. Além disto, vários sindicatos construíram, com os recursos advindos do imposto sindical, sedes campestres que proporcionariam aos filiados e suas famílias formas variadas de lazer, facilitando a adesão de um número cada vez maior de sindicalizados.

No entanto, este novo modelo sindical só pode ser amplamente conhecido pelos trabalhadores a partir de 1943, quando o Ministério 
do trabalho, sob o comando de Alexandre Marcondes, implementou campanhas de propaganda e sindicalização, através das quais divulgava entre os assalariados os benefícios que a filiação aos sindicatos thes proporcionaria (GOMES, 2005a). Neste mesmo ano, com a criação da Comissão Terceira de Orientação Sindical (Decreto-Lei 5199), institucionalizou-se a ação estatal de mobilização sindical. A partir daí, o corpo de associados de cada sindicato oficial foi progressivamente ampliado.

Para Angela Gomes, é apenas neste período que o corporativismo ganha relevância e torna-se predominante como modelo de intermediação de interesses. Desde então, supostamente, o controle estatal sobre os trabalhadores, por via dos sindicatos oficiais, iria se tornar mais abrangente, possibilitando ao Estado abandonar os mecanismos coercitivos amplamente utilizados durante o Estado Novo e estabelecer um controle legítimo sobre o contingente de trabalhadores associados aos sindicatos oficiais.

Essa chave analítica permite associar o corporativismo à brasileira não ao autoritarismo, mas à democracia. À medida em que os sindicatos revelam-se capazes de atrair adeptos, a estrutura corporativa passa a adquirir alguma consistência, tornando possível a transição sem rupturas do pós-45. Nestes termos, o corporativismo apresenta-se não como parte do sistema autoritário estadonovista, mas como uma política de mobilização acompanhada de um discurso ideológico que pretendia envolver todos os setores da sociedade no projeto de industrialização nacional (GOMES, 2005a). Desde então, apesar da resistência apresentada por alguns segmentos de assalariados à ideia de um sindicalismo de Estado, os dados revelam um aumento progressivo do número de sindicatos oficiais, assim como do volume de filiações (VIANNA, 1999).

De 1945 a 1964, o Brasil conheceu um formato híbrido, no qual um pluralismo mitigado no plano político - note-se a interdição do PCB -, convivia com a ordem sindical corporativa. Embora obstruísse a afirmação de uma identidade operária autônoma e a realização plena da democracia representativa, com partidos políticos cumprindo o papel de canalizar para o ambiente institucional as demandas advindas dos diversos segmentos sociais, a presença da estrutura sindical corporativa não impediu a mobilização dos trabalhadores, que no decorrer da Democracia de 46 foi crescente. Nem sempre a mobilização e o protesto consistiram em uma iniciativa do sindicato, mas, por diversas vezes, o sindicato acabou encampando lutas por direitos surgidas a partir da 
ação espontânea de membros das bases sindicais. Também não foi incomum, no período, a radicalização, por iniciativa das bases sindicais, de manifestações convocadas pelos sindicatos.

Com efeito, as greves foram frequentes no período e, se até o final dos anos 50 constituíram-se, fundamentalmente, como movimentos empreendidos por categorias profissionais específicas, na passagem aos anos 60 as greves gerais, de conteúdo notadamente político, tornaramse significativas (SANDOVAL, 1994). Por outro lado, o judiciário trabalhista, tributário em suas origens da estratégia de promover a conciliação em detrimento do conflito entre as classes, transformouse amiúde em arena de disputas, nem sempre passíveis de solução em primeira instância. Tampouco é possível afirmar que de forma generalizada os acordos prevaleceram sobre os demais resultados obtidos nos tribunais, ainda que isso possa se verificar em determinados casos (LOBO, 2013). Por fim, cumpre lembrar que neste período um sistema partidário constituído por partidos recém criados possuía traços bem delineados, apresentava índices crescentes de identificação e lealdade e estava em vias de consolidar-se às vésperas do golpe de 64 (LAVAREDA, 1991). Não há qualquer estudo que demonstre de forma consistente a impossibilidade de desenvolvimento de um padrão de ação suplementar entre partido e sindicato, tal como se verificou no neocorporativismo europeu. Ao contrário, o PTB, que surge como um partido dos Institutos de Previdência e do Ministério do Trabalho, estreitamente associado à figura de Vargas, adquire crescente conteúdo trabalhista e se torna progressivamente um legítimo representante dos interesses dos assalariados (DELGADO, 2011).

Não é o caso, considerando os limites dessa abordagem, de estender ainda mais considerações acerca do período compreendido entre 1945 e 1964, de todo modo já há algum tempo visitado por historiadores, sociólogos e cientistas políticos, cujos estudos têm, em certos casos, contribuído para relativizar as análises processadas a partir da noção de populismo e de passividade e subordinação das camadas assalariadas brasileiras, descortinando um mundo de ações, associações, organizações e mobilizações que extrapolam os limites do corporativismo em seu viés autoritário.

Tais considerações autorizam uma opção por refletir não apenas acerca dos limites que o corporativismo representa para a democracia, em seus aspectos políticos e sociais, apontando para a necessidade de superá-lo. Ao contrário, ainda que não se possa perder de vista sua origem autoritária e determinados vícios e falhas do corporativismo brasileiro, 
pelo exposto me parece pertinente refletir acerca das possibilidades de aperfeiçoamento do modelo para que ele possa efetivamente se orientar no sentido de promover a conciliação, o compromisso e um pacto assentado sobre bases materiais reais.

\section{Balanço e perspectivas}

Oliveira Viana chamara a atenção para a importância de se compreender as peculiaridades brasileiras a fim de melhor avaliar as possibilidades de importação de um modelo vindo de fora ou, se constatada essa impossibilidade, criar um modelo genuíno e totalmente adequado às necessidades e possibilidades da sociedade brasileira ${ }^{13}$. Neste sentido, buscou analisar a sociedade brasileira a partir de um registro que o levou ressaltar seus traços menos nobres, a fim de pensar um modelo que, considerando aquelas características, melhor se adaptasse à realidade do país.

Não é o caso aqui de discutir ou opinar acerca da acepção de Oliveira Viana sobre a sociedade brasileira. O que cumpre marcar é que, a despeito de ter sido preterido em suas proposições talvez mais pertinentes em torno do modelo a ser construído, ao cabo, o processo de implantação do corporativismo no Brasil, compreendido em suas múltiplas dimensões, resultou em um formato peculiar, com elevada capacidade de sobrevivência e adaptação, convivendo com diferentes regimes políticos experimentados desde a década de 1930. Passou pelo Estado Novo, pela Democracia de 46, pelo regime burocráticoautoritário, pela Nova República, pelo Neoliberalismo, e chega aos dias atuais sem que seus pilares tenham sido abalados. Em termos constitucionais, verificam-se traços do corporativismo já na Constituição de 1934 e desde então, não obstante as críticas, tem sobrevivido às diversas cartas constitucionais, quer democráticas ou autoritárias. Nesse sentido, a estabilidade da estrutura corporativa se destaca, por contraste com a instabilidade de parte substantiva das instituições que constituem o complexo institucional brasileiro.

Essa característica do corporativismo brasileiro, sua estabilidade, sua capacidade de adaptação, impõe, no mínimo, que ele seja percebido como um dado da realidade política brasileira de difícil superação. Diante disso, talvez seja mais producente e menos oneroso buscar

13 Uma excelente análise acerca das formulações de Oliveira Viana pode ser encontrada em ABREU, 2012. 
compreender suas falhas, seus limites, mas também suas potencialidades como mecanismo capaz de favorecer uma maior concertação entre Capital, Trabalho e Estado. Há certamente muitos aspectos que não podem ser negligenciados e que de modo mais ou menos intenso têm sido há muito apontados pela literatura pertinente.

Seja em cenários predominantemente democráticos ou ditatoriais, o formato que se desenvolveu no Brasil permite uma ingerência continuada do Estado nos organismos sindicais, quer reduzida apenas ao cumprimento dos dispositivos legais (recolhimento e repasse da contribuição sindical, por exemplo), quer exacerbada através da adoção de procedimentos explicitamente autoritários, como os adotados durante o regime burocrático-autoritário, inaugurado pelo golpe militar de $1964^{14}$. Da mesma forma que o grau e o formato de intervenção do Estado nos organismos sindicais variam de acordo com o regime político predominante, o acesso dos dirigentes sindicais à burocracia estatal também se altera. Embora o corporativismo à brasileira jamais tenha consistido em um sistema formado por conselhos consultivos e deliberativos, formuladores de políticas, altamente representativos segundo critérios técnicos e ocupacionais, no período compreendido entre 1945 e 1964 o modelo expressava-se de forma mais inclusiva se comparado ao pós-64, quando os sindicatos foram transformados em agência basicamente assistencialistas e seus dirigentes, além de proibidos de exercer uma prática mobilizadora e reivindicativa, não tinham qualquer influência na definição das políticas públicas. Neste período, se possível identificar a presença de corporativismo no Brasil, ele foi notadamente exclusivo (STEPAN, 1980), ou, como sugere Tavares de Almeida (1983), uma via de mão-única.

Assim, em contraste com o neocorporativismo, ou corporativismo social de acordo com a tipologia proposta por Schmitter (1974), os sindicatos brasileiros em qualquer contexto sempre exerceram baixa influência na consecução de políticas públicas. Além disto, a estrutura sindical corporativa, aqui, não resultou de um consenso estabelecido entre o Estado e entidades sindicais autônomas. Como ordem imposta de cima para baixo, a introdução do modelo sindical corporativo no Brasil foi marcada por procedimentos autoritários por parte do Estado e se

\footnotetext{
14 Até 1988 o Estado dispunha da prerrogativa de interferir diretamente nos assuntos internos aos sindicatos. A Constituição Federal de 1988, entretanto, no inciso I do artigo $8^{\circ}$, proíbe o poder público de intervir nas organizações sindicais. Não obstante, determina a arbitragem judicial obrigatória. Desta forma, observa-se que houve afrouxamento do controle dos governos sobre as entidades sindicais, mas não do Estado. (BOITO,1991)
} 
pautou mais pelo controle sobre os trabalhadores do que pela tentativa de promover efetivamente uma conciliação baseada em diálogos e negociações substantivas, como referido acima. Essa característica mitiga as chances de efetivação de um pacto entre os principais atores sociais, capaz de proporcionar estabilidade às políticas governamentais, as quais, por isso mesmo, dificilmente se transformam em políticas de Estado.

Ademais, a natureza segmentária da estrutura corporativa brasileira, embora tenha sido identificada com o regime burocrático-autoritário, perpassa toda a história das relações entre Estado e sociedade no Brasil desde os anos 1930. Na prática, isso se traduz no acesso diferenciado de trabalhadores e empresários às instâncias decisórias do aparelho de Estado. Além disso, o corporativismo não impediu que o empresariado mantivesse o funcionamento paralelo de entidades autônomas aos organismos oficiais, ao passo que as entidades sindicais autônomas existentes à época da implantação do corporativismo foram todas fechadas ou incorporadas à estrutura oficial, apesar da resistência de dirigentes sindicais (GOMES, 2014; VIANNA, 1999).

Assim, mesmo que, a partir de 1932, várias leis sociais e trabalhistas tenham sido promulgadas, e, embora sejam a expressão clara de antigas reivindicações do movimento sindical, foram concebidas para serem recebidas como dádiva e não como resultado de uma negociação entre os atores envolvidos. Por outro lado, em certos casos, ainda que a fixação da lei seja precedida de debate e conhecida a posição dos atores, prevalece uma perspectiva unilateral, em detrimento de um acordo informado pela necessidade de se considerar os interesses de todos os atores envolvidos, evidenciando que certas leis faziam parte de um conjunto de medidas destinadas a instaurar um novo modo de acumulação.

Nesse ponto, o processo que culminou na lei do salário mínimo é elucidativa. As demandas operárias em torno da questão exigiam a implementação do salário mínimo profissional. As proposições empresariais indicavam o critério "biológico", isto é, o salário mínimo vinculado à garantia de uma renda que assegurasse a simples reprodução da força de trabalho, desconsiderando critérios relativos a cada profissão ${ }^{15}$. Embora definida pela Constituição de 1934 a noção do salário mínimo profissional, na regulamentação efetiva do salário

${ }^{15}$ Uma descrição minuciosa do debate sobre o salário mínimo, envolvendo entidades empresariais, de trabalhadores e a burocracia de Estado, encontra-se em GOMES, 2014, p. 303 et seq. e VIANNA, 1999, p. 235 et seq. 
mínimo prevaleceu a perspectiva do mínimo biológico. Assim, num quadro em que a grande maioria das indústrias - em função da acelerada industrialização - remunerava seus operários com níveis mais elevados que o mínimo, garantia-se a ampliação do mercado potencial para a indústria com a generalização do princípio da remuneração monetária do trabalho. Sem produzir ônus para a indústria, o salário mínimo, por outro lado, definia um modelo de remuneração que dissociava o salário da produtividade. A distância entre um e outro teria sido um dos principais elementos da aceleração do processo de industrialização ulterior (SINGER, 1977).

De modo que a ausência de bases consensuais na montagem da estrutura corporativa, seu caráter segmentário, o recurso a mecanismos coercitivos impostos aos sindicalistas que resistiram ao atrelamento dos sindicatos ao Estado são manifestações claras da forma autoritária que marcou a introdução da ordem sindical corporativa no Brasil dos anos 30 e oferecem os contornos de um modelo distinto daquele que se desenvolveu paralelamente ao welfare state europeu.

Contudo, reitero que reconhecer tais limites não implica, de forma alguma, nos termos da presente abordagem, em corroborar uma percepção exclusivamente negativa acerca do modelo e tampouco do movimento de trabalhadores que se fez dentro e fora dos espaços institucionais. Inúmeros estudos de caso têm demonstrado não apenas que a despeito de seu caráter heterônomo os sindicatos oficiais desde de suas origens constituem um lugar privilegiado para a formulação de demandas e de mobilização, mas também muitas vezes as ações mobilizadoras partem de fora dos sindicatos, os quais acabam sendo pressionados a aderir e a assumir a liderança do movimento ${ }^{16}$. Tampouco trata-se de propor a refundação de um certo liberalismo que marcou a evolução do país até 30 ou postular a ruptura total com os padrões corporativos vigentes na estrutura sindical. Trata-se, outrossim, de chamar a atenção para a necessidade de se refletir acerca da realidade nacional e do sistema institucional brasileiro considerando aquilo que se faz presente e que, tendo se tornado parte de nossa cultura política, deve ser encarado como algo a ser aperfeiçoado, aprimorado, levando-se em conta, inclusive, algumas proposições pertinentes, encontradas na literatura analisada, referentes à necessidade não de romper com a ordem corporativa, mas de aprofundá-la ${ }^{17}$.

\footnotetext{
16 Ver por exemplo FORTES et al., 1999; SANTANA e RAMALHO, 2001.
}

17 A exemplo de REIS, 1988. 


\section{Conclusão}

Em certas democracias europeias, o desenvolvimento de mecanismos corporativos de intermediação de interesses, após 1945, não eliminou as organizações autônomas dos trabalhadores e associou-se à busca de estabilidade para a vida econômica, a partir de um consenso básico quanto aos ganhos mútuos que empresários e trabalhadores poderiam obter com a expansão capitalista. A obtenção deste consenso se deu num quadro em que o conflito entre esses atores - através de sindicatos e partidos - alcançou um certo limite de tensão que os levou a soluções de compromisso, expressas no Welfare State. Tal não ocorreu no Brasil por razões diversas, entre as quais a persistência de um modelo de intermediação de interesses que, ao contrário do que vinha se verificando em países europeus, e também daquilo que de certa forma informara a defesa do modelo por um Oliveira Viana, revelou baixa capacidade catalisadora, subtraindo do horizonte da Democracia de 46 a obtenção de um consenso que favorecesse o estabelecimento de um pacto em torno da continuidade do desenvolvimento capitalista com viés redistributivo.

Se durante o Estado Novo os atores foram chamados a jogar um jogo de soma positiva, com benefícios mútuos, o que teria inclusive contribuído para a construção de uma memória positiva acerca de Vargas (GOMES, 2005b), a despeito do autoritarismo que marcou boa parte de sua primeira passagem pela presidência, o que se desenvolve a partir daí é um afastamento progressivo das perspectivas de um pacto, em que pese a presença de um acordo tácito entre empresários e trabalhadores que está na base da chamada "coalizão inflacionária" (LOBO, 2010). De 45 a 64 tal afastamento não impediu a obtenção de conquistas trabalhistas, mas essas resultaram sobretudo da mobilização dos setores populares, e particularmente dos trabalhadores, que se refletiu tanto no plano mais imediato das relações sociais que se processaram fora dos arranjos corporativos, como no plano das instituições típicas da democracia representativa, sem desconsiderar, ainda, as disputas realizadas no âmbito do judiciário trabalhista, instituição essencialmente corporativa. A resposta empresarial ao fortalecimento da organização dos trabalhadores, de sua parte, esteve longe de uma perspectiva de convergência. Ao contrário, na passagem aos anos 60, o que se assiste é uma crescente polarização, num cenário em que o empresariado nacional se associa progressivamente ao capital estrangeiro. 
Portanto, se nas democracias do ocidente europeu o corporativismo foi a saída encontrada para restabelecer o equilíbrio de forças em uma conjuntura de fortalecimento do poder de pressão dos trabalhadores, no Brasil o aumento do poder de pressão dos trabalhadores terminou por conduzir a uma ruptura institucional. Lá, diante da constatação de que a própria economia estava em risco em face da polarização, fixou-se um certo consenso em torno da necessidade de se restabelecer a capacidade de interlocução entre os agentes e a saída encontrada foi a criação de organismos paralelos às instituições representativas, num jogo de soma positiva em que todos saíram ganhando. No Brasil, as conquistas recém mencionadas não resultaram no aprimoramento dos processos de negociação entre os atores dentro de arenas institucionalizadas. Ao contrário, aprofundou-se o afastamento, o que se agravava a cada nova vitória eleitoral do PTB. A saída para restabelecer o "equilíbrio de forças", do ponto de vista do empresariado, foi uma ruptura institucional que ocasionou a exclusão dos setores populares de todas as instâncias decisórias, corporativas ou representativas, afetando em cheio os interesses dos trabalhadores.

Em que pesem as permanências apontadas com propriedade por Martinho (2008), a ruptura com o processo de incremento salarial e bem estar dos trabalhadores urbanos é uma realidade que não pode ser contraditada e que, nos termos de Gomes, reforça a memória negativa acerca do Regime Militar, por contraste com a memória positiva a respeito de Vargas, acima referida (GOMES, 2005b). É fato que no pós-64 a estrutura sindical corporativa manteve-se intacta, mas agora ainda mais distante uma roupagem solidarista, o que, simbolicamente, expressa-se na eliminação do instituto da estabilidade no emprego e na criação do FGTS, que libera o apetite empresarial no interior de um formato que sobre o movimento operário apresentava-se como puro controle. Mas é importante salientar que, a despeito da exclusão política dos coletivos de trabalhadores, a preservação da estrutura corporativa nesse período contribuiu para a rápida rearticulação do movimento operário a partir de meados dos anos 70, e, sobretudo, assegurou aos trabalhadores a possibilidade de buscar seus direitos no âmbito da Justiça do Trabalho, mesmo em um ambiente nacional marcado pelo autoritarismo.

Em síntese, me parece que o dado mais relevante no debate sobre o corporativismo não é que a estrutura sindical corporativa impediu o desenvolvimento da ação autônoma dos trabalhadores, ao passo que para os empresários o Estado jamais chegou a interditá-la (BOSCHI, 1979; DINIZ, 1978), configurando um modelo de intermediação de interesses 
maneta, bifronte e segmentado. Conquistas foram obtidas a despeito deste formato. O mais significativo é que, tal como foi montado, não foi capaz de induzir à cooperação e de conter em certos momentos a crescente polarização e o distanciamento da perspectiva de um pacto. Do ponto de vista desta abordagem, pois, mais do que apontar saídas voltadas para a redução do Estado e a introdução de medidas orientadas para o mercado, sugere-se refletir sobre o corporativismo dentro de uma perspectiva voltada para a criação de mecanismos que permitam ao modelo induzir os contendores à cooperação e inibir a prevalência de comportamentos capazes de mitigar os resultados de políticas e de acordos informados por uma perspectiva de ganhos mútuos. Por outras palavras, é preciso criar dispositivos que capacitem as organizações a estabelecer acordos, mas que também as tornem capazes de assegurar que seus membros não irão evadir-se desses acordos.

A ausência desses mecanismos gera um quadro de incerteza entre os atores, os quais tendem a se comportar segundo uma lógica direcionada à maximização de ganhos, num jogo de soma zero que tende a resultar em benefícios efêmeros aos vencedores de cada lance. Benefícios assim conquistados dificilmente se sustentam no médio prazo, na medida em que o vencido continuará se comportando de modo a tentar reverter o jogo ou, na ausência de mecanismos que o obriguem a acolher o resultado, tenderá a evadir-se, em prejuízo da própria saúde econômica do país, a qual - a menos que se vislumbre uma ruptura com o capitalismo ou com a democracia, o que não parece avizinhar-se depende do consentimento dos atores envolvidos em torno da fixação de bases materiais que lhe deem sustentação.

\section{Referências}

ABREU, Luciano Aronne. Autoritarismo e corporativismo no Brasil. Anais do XI Encontro Regional da ANPUH-RS. Rio Grande: FURG, 2012.

ALVES, Maria Helena Moreira. Estado e oposição no Brasil. Petrópolis: Vozes, 1984. BOITO Jr, Armando. O sindicalismo de estado no Brasil: uma análise crítica da estrutura sindical. Campinas: Ed. da UNICAMP/SP-HUCITEC, 1991.

BOSCHI, R.R. Elites industriais e democracia. Rio de Janeiro: Graal, 1979.

CAMARGO, Aspásia; DINIZ, Eli. Continuidade e mudança no Brasil da Nova República. São Paulo: Vértice/Revista dos Tribunais, 1989.

DELGADO, Lucília N. O PTB: do Getulismo ao Trabalhismo. São Paulo: LTr, 2011.

DINIZ, E. Empresariado, Estado e capitalismo no Brasil: 1930-1945. Rio de Janeiro: Paz e Terra, 1978. 
DUARTE, Nestor. A ordem privada e a organização politica nacional. São Paulo: Companhia Editora Nacional, 1939.

FAORO, Raimundo. Os donos do poder. Porto Alegre: Globo, 1958.

FORTES, A. et al. (Org.). Na luta por direitos. Campinas: Ed. UNICAMP, 1999.

FURTADO, C. Formação econômica do Brasil. São Paulo: Nacional, 1975.

GOMES, Angela Castro. A invenção do trabalhismo. Rio de Janeiro: FGV, 2005a.

. Autoritarismo e corporativismo no Brasil: o legado de Vargas. Revista USP, São Paulo, n. 65, 105-119, mar-maio 2005b.

. Burguesia e trabalho. Rio de Janeiro: 7 Letras, 2014.

LAVAREDA, A. A democracia nas urnas. Rio de Janeiro: IUPERJ/Rio Fundo, 1991.

LOBO, Valéria M. Democracia e corporativismo no Brasil, 1995. Dissertação (Mestrado em Ciência Política) - Universidade Federal de Minas Gerais, Belo Horizonte 1995.

. Fronteiras da cidadania. Belo Horizonte: Argvmentvm, 2010.

Por que tecelões e metalúrgicos vão aos tribunais? - posição da indústria e reclamações ao judiciário trabalhista entre as décadas de 1940 e 1960. Revista Mundos do Trabalho, Florianópolis, v. 5, n. 10, 183-198, jul.-dez. 2013.

MARSHALL, T. H. Cidadania, classe social e status. Rio de Janeiro: Zahar, 1967.

MARTINHO, Francisco Carlos Palomanes. Estado Novo, Ditadura Militar, Corporativismo e Identidade Nacional. IX Congresso Internacional da Brazilian Studies Association (BRASA). New Orleans/Loisiania: Tulane University, mar. 2008.

MARTINS, L. A revolução de 1930 e seu significado político. In: Revolução de 30 Seminário Internacional. Brasília: Ed. da UNB, 1983.

MELLO, João Manoel Cardoso. O capitalismo tardio. São Paulo: Brasiliense, 1984.

MICHELS, Robert. Sociologia dos partidos políticos. Brasília: Ed. da UNB, 1982.

MOORE JR, Barringthon. As origens sociais da ditadura e da democracia. Lisboa: Cosmos, 1975.

NORONHA, Eduardo. O sistema legislado de relações de trabalho no Brasil. Dados, Rio de Janeiro, v. 43, n. 2, 2000.

OFFE, Claus. A Democracia partidária competitiva e o Welfare State Keynesiano. In: OFFE, C. (Org.). Problemas estruturais do estado capitalista. Rio de Janeiro: Tempo Brasileiro, 1984.

Trabalho \& sociedade: problemas estruturais e perspectivas para o futuro da sociedade do trabalho. Rio de Janeiro: Tempo Brasileiro, 1991.

OFFE, Claus; WIESENTHAL, Helmut. Duas lógicas da ação coletiva: anotações teóricas sobre classe social e forma organizacional. In: OFFE, Claus. Problemas estruturais do estado capitalista. Rio de Janeiro: Tempo Brasileiro, 1984.

OLIVEIRA, F. A economia brasileira: crítica da razão dualista. Petrópolis, Vozes/ CEBRAP, 1981.

PANITCH, Leo. Os Sindicatos e o Estado no Capitalismo Avançado. Revista de Cultura e Política, Rio de Janeiro, CEDEC/Paz e Terra, n. 5-6, abr.-jun. e jul.-set. 1981.

PELAEZ, C. M. As Consequências Econômicas da Ortodoxia Monetária Cambial e Fiscal no Brasil entre 1889 e 1945. Revista Brasileira de Economia. Rio de Janeiro, p. 50-82, jul.-set. 1971. 
PZERWORSKI, A. Capitalismo e social democracia. São Paulo: Companhia das Letras, 1989.

REIS FILHO, Daniel Aarão. O colapso do colapso do populismo: ou a propósito de uma herança maldita. In: FERREIRA, J. (Org.). O populismo e sua história: debate e crítica. Rio de Janeiro: Civilização Brasileira, 2001. p. 319-377.

REIS, Fabio Wanderley. Consolidação democrática e construção do Estado. In: REIS, F.W.; O’DONNELL, G. (Org.). Democracia no Brasil: dilemas e perspectivas. São Paulo: Vértice, 1988.

SANDOVAL, Salvador. Os trabalhadores param. São Paulo: Ática, 1994.

SANTANA, M. A.; RAMALHO, J.R. Trabalho e tradição sindical no Rio de Janeiro. Rio de Janeiro: DP\&A, 2001.

SANTOS, Wanderlei Guilherme. Ordem burguesa e liberalismo político. São Paulo: Duas Cidades, 1978.

SCHMITTER, Philippe C. Still the century of corporatism? The Rewiew of Politics, v. 36, n. 1, p. 85-131, jan. 1974.

SCWARTZMAN, Simon. Bases do autoritarismo brasileiro. Rio de Janeiro: Campus, 1982.

SILVA, S. Expansão cafeeira e origens da indústria no Brasil. São Paulo: Alfa-Ômega, 1976.

SINGER, P. A crise do “Milagre”. Rio de Janeiro: Paz e Terra, 1977.

STEPAN, A. Estado, corporativismo e autoritarismo. Rio de Janeiro: Paz e Terra, 1980.

TAVARES, M. C. Da substituição de importações ao capitalismo financeiro. Rio de Janeiro: Zahar, 1983.

TOLEDO, Caio Navarro. ISEB: fábrica de ideologias. São Paulo: Ática, 1982.

VELHO, Otávio Guilherme. Capitalismo autoritário e campesinato. São Paulo: DIFEL, 1976.

VIANNA, Luis Werneck. Liberalismo e Sindicato no Brasil. Belo Horizonte: UFMG, 1999.

VILlelA, A. E SUZIGAN, W. Política do governo e crescimento da economia brasileira: 1889-1945. Rio de Janeiro: IPEA-INPES, 1973.

Enviado em: 23 de novembro de 2015

Aceito em: 14 de janeiro de 2016

\section{Autor/Author:}

VALÉRIA MARQUES LOBO <valerialobo.ufjf@gmail.com>

- Professora do Departamento de História da Universidade Federal de Juiz de Fora (UFJF). Autora de Fronteiras da Cidadania: sindicatos e (des)mercantilização do trabalho no Brasil (Argvmentvm, 2010). Suas pesquisas relacionam-se à democracia, relações sociais, direito do trabalho, sindicalismo.

- Professor at the Universidade Federal de Juiz de Forab (UFJF), Department of History. She is the author of Fronteiras da Cidadania: sindicatos e (des)mercantilização do trabalho no Brasil (Argvmentvm, 2010). Her research focuses on social relations, democracy, labor law, unionism. 